\title{
Preliminary Investigations into the Factors Affecting Successful Implementation of Project Management Frameworks and its Effects on Project Success: Evidence from Ghana
}

\author{
Ivy Hawah Taana* \\ Limkokwing University of Creative Technology, \\ Cyberjaya, Malaysia
}

\author{
Valliappan Raju \\ Limkokwing University of Creative Technology, \\ Cyberjaya, Malaysia
}

\begin{abstract}
Whether undertaken by a public or private organization, the successful completion of every project is of primary concern. However, literature has confirmed that most project success depends on adhering to good practices and are keenly documented in the Project Management Frameworks (PMFs). The purpose of this study is to explore the factors that affect the implementation of PMFs in Ghana. This is motivated by the dearth of academic literature concerning PMFs and their successful implementation in Ghana. A conceptual framework was developed grounded on the Capability Maturity Model (CMM) and the Critical Success Factors (CSFs) theory to achieve this aim. Four independent variables and the dependent variable were hypothesized to be tested to establish the success factors affecting PMFs implementation. Data were collected from 105 project management consultants, contractors, and other key stakeholders in Ghana and analyzed to establish the relationships between the hypothesized constructs. The findings indicate that Stakeholder Involvement (SI) and Top Management Support (TMS) influence the adoption of PMFs. However, Acceptability and Organizational Maturity (OM) does not influence the adoption of PMFs. Moreover, PMFs does not influence Project Success. This preliminary study has given us insights into the factors to consider when adopting PMFs in Ghana. Practically, key stakeholders should encourage project management consultants and contractors to accept the PMFs, which, when adhered to, will lead to project success which is contrary to what this study found.
\end{abstract}

Keywords: Project management, PMFs, implementation, CSFs, CMM, Ghana

Received: 23 May 2020; Accepted: 15 July 2020; Published: 25 October 2020

\section{INTRODUCTION}

All over the world, projects are being carried out regularly by public and private organizations (both profit and non-profit). Such projects can be categorized into software, construction, health-related, etc. However, Maylor, Brady, Cooke-Davies, and Hodgson (2006) say projects have had significant growth from diverse sectors and industries of the worlds economy. This is confirmed by Gomes and Romão (2014) who noted that there is a continuous increase in the number of development programs being undertaking through projects.

However, Project Management became popular in the 1980s, although it was not a simple method to use because it used various means of directing and monitoring human activities that deal with projects. Therefore, project management was used in the service sector, the mass production industry, and the public sectors of the economy (Banica, Radulescu, Rosca, \& Hagiu, 2017; Ferreira, Ferreira, \& Mariano, 2018). Amponsah and Darmoe (2014) noted that Projects across

\footnotetext{
${ }^{*}$ Correspondence concerning this article should be addressed to Ivy Hawah Taana, Limkokwing University of Creative Technology, Cyberjaya, Malaysia. E-mail: ivytaana@yahoo.com

(c) 2020 The Author(s). Published by KKG Publications. This is an Open Access article distributed under a Creative Commons AttributionNonCommercial-NoDerivatives 4.0 International License.
} 
different parts of the globe does not reach its completion stage as they are usually abandoned and causing financial loss due to insufficient funds, inappropriate project management experts and so on, but extant literature shows that many governments and organizations are implementing PMFs that are helping them achieve high project success rates. There are several project management methodologies, frameworks, and processes that have been developed and being used in managing projects by project management consultants who established associations like the Project Management Institute (PMI) and the International Project Management Association (IPMA) in other to see to the challenges and train professionals in the field of practice.

To this effect, these associations have published various guides like the Project Management Body of Knowledge (PMBOK Guide) in various volumes for over 30 years now and we also have the Projects IN Controlled Environment (PRINCE2) (Banica et al., 2017).

The frameworks in this research study are the means of communication between the practitioners (association bodies) and the project managers. Thus, it serves as a source of process and ethical guidelines. The PMF is very crucial to the accomplishment of a project, it is also the unifying force of the project team. Researchers have also noted a positive correlation between PMFs and Project success (Kwofie, 2015; Foss \& Pedersen, 2019).

Professor Gyan-Baffour, "the Deputy Minister for Finance and Economic Planning” 2016, in a speech (July 2016) for "project managers by African Development Bank" in Ghana Accra, noted that "many projects in the public and private sectors of the Ghanaian economy have been falling since independence". This may be due to "lengthy approval procedures, the existing administrative system", inadequate change management practices, "lack of ownership, lack of authority, poor estimation of activity cost", etc. He also noted the fact that project implementation in the country was declining which caused a substantial loss to the country and thereby needs to improve (Daily Graphic, July 2006).

Even though Ghana has a few Management Consultants and managers involved in diverse projects in various industries from both private and public sectors of Ghanas economy, projects keep on failing, and much is not seen as it is either delayed or uncomplete work (Amponsah \& Darmoe, 2014). This is worrying because about $60 \%$ of developmental works are gained from donner supports and unsuccessful projects would mean dinners redrawing their funding.

This study is necessary as there is a lack of literature to theoretically assess the factors influencing PMFs and its effects on project success. Thus, this study aims at contributing to the body of knowledge in terms of the project management literature with a vital look at the PMFs and its relation to project success hence these research objectives.

1. To investigate the factors affecting PMFs implementation in Ghana

2. To assess the effect of PMFs on the success of projects in Ghana

This study seeks to address the following questions based on the specific objectives above.

1. What are the factors affecting PMFs implementation in Ghana?

2. What impact does PMFs have on project success in Ghana?

In practice, the study aims to explore the contextual factors that affect PMFs implementation in the context of a developing country and also the identification of the main factors to focus on when implementing PMFs will be revealed through the analysis and the findings of the study. The identified factors will be a guide for other organizations that strives to adopt and implement PMFs so as not to waste resources. The results will also be used to create awareness for project consultants and contractors as to the best practices to follow when embarking on projects to achieve high project success rates.

\section{LITERATURE REVIEW}

This study is about the adoption of PMFs and project success. Various institutions have different definitions for projects. Weaver (2007) describes a project as something with a beginning and an end.

The PMI defines Project Management as the application of knowledge, skills, tools, and techniques to project activities to meet the project requirements (Project Management Institute, 2000). And lastly, the PRINCE2 describes a project as a temporary organization that is created for delivering one or more business products according to an agreed Business Case.

In defining Project Management, according to PMBoK (5th edition), Project Management is the application of knowledge, skills, tools, and techniques to a project activity to meet the project requirement.

Also, Kerzner (2009), see Project Management as the planning, organizing, directing and controlling of company resources for a relatively short-term objective that has been established to complete specific goals and objectives. He 
continues to say that project management utilizes the systems approach to management by having functional personnel (the vertical hierarch) assigned to a specific project (the horizontal hierarchy).

These definitions show projects are temporary (start and ends) and are established to accomplish a specific task (achieving something new). Thus, organizational activities can either be a project or a process. Therefore, organizations need to focus on when making strategic decisions of the project because of their unique nature.

Project management concept in Ghana was first practiced in the late 80s by Social Security and National Insurance Trust (SSNIT) and was pioneered by AmoaMensah who first proposed the impression to the SSNIT as It was common for most of these projects to experience time and cost overruns of more than $100 \%$. Naturally, the Government of Ghana (GoG) and the public whose contributions were being used for such investments became alarmed and lost all confidence in SSNIT as a housing provider (Ofori \& Deffor, 2013). It was during this trying period that the SSNIT appointed their first project manager on an MHBP in Ghana.

The use of PMFs as tools for aiding project success has become a common phenomenon. However, extant literature has revealed that Africas political conditions may affect PMFs Implementations (Muriithi \& Crawford, 2003). For this reason, it has been evaluated and tested scientifically that the use of the western Project Management techniques will not enhance project success in Africa (Grisham, 2009). Hence the need to assess if the adoption and implementation of this framework will lead to project success in Ghana.

Since projects are generally perceived to be unique, it cannot be expected that the same set of processes and methods will foster the success of every project (Ahlemann, Teuteberg, \& Vogelsang, 2009). Best practices in project management contribute to the achievement of goals, but project managers need to determine which project management methods can be generally applied and those that are appropriate in specific situations. Project managers also need to be able to adapt to the international standard to the cultural differences which appear in different areas or countries.

\section{Underpinning Theories}

The underpinning theories for this paper are the Critical Success Factor (CSF) and CMM. These theories were used because the research is about the successful implementation of PMFs and a combination of theories gives a better understanding of the phenomenon being investigated.

From literature, it has been proven that CSFs are very good at measuring the success of an activity (Osei-Kyei \& Chan, 2015; E. K. Owusu, Chan, DeGraft, Ameyaw, \& Robert, 2019). Secondly, most writers in the field of project management use CSF when writing about project success. This model has been tested and proven in the area of management studies that it is very important to consider CSFs that will help an activity or organization to grow and also achieve effective and sustainable goals (Yalegama, Chileshe, \& Ma, 2016).

Iqbal, Khan, and Minhas (2018), Hu and Gao (2019), Ofori and Deffor (2013) and many more asserted that CMM is widely used when implementing an activity or project of a sort. It shows the particular activity that is necessary at a certain stage of an activity, organizations must be extra careful when implementing a methodology in the system that would be used for the lifetime of the organization. This means that implementation is a critical activity of an organization that should be carefully looked at (Košt'álová \& Tetřevová, 2018; Nishant, Srivastava, \& Bahli, 2020; Shaikh et al., 2019). It is on this note that the researcher decided to use the CMM as the second theory for the research to ensure that the implementation process is carefully and smoothly carried out. Therefore, this study is justified by using these two theories (CSFs and CMM) considering the fact the study is at the organizational level.

\section{CSFs Theory}

According to Rockart (1982), CSFs are the few key areas of activity where favorable results are necessary for a manager to reach his/her goals.

Several researchers used the idea of CSFs to improve upon and to suggest the best ways of implementing PMFs for infrastructure development (Liu, Liu, \& Yang, 2020). For instance, CSFs are used in the infrastructure sector where Project Management practices are key, the transportation, telecommunication, energy sectors are not left out (Abdul-Aziz \& Kassim, 2011; Liu, Love, Smith, Regan, \& Davis, 2015). CSFs are also used at various stages within the PMFs. For instance, Ng, Wong, and Wong (2012) studied the success factors at the feasibility stage of projects while Tang and Shen (2013) looked at the success factors at the briefing stages of Public-Private-Partnership (PPP).

However, looking at the wide range of studies on CSFs for PMFs, practitioners and researchers are finding it hard to find the most important CSFs for the execution of PMFs that would be unified across various countries and 
sectors. Finally, in their quest to investigate and identify the factors that encourage the successful implementation of Information Technology Governance (ITG) upon using the CSF, Alreemy, Chang, Walters, and Wills (2016) concluded that the CSFs have been discussed by many sources and expressed in different meanings, terms and under different topics, but required a thorough analysis of these sources to extract the most important and related factors this is because there are a lot of factors to be considered and this was supported by Osei-Kyei and Chan (2015) when they observed that organizations must concentrate on CSFs that best works in enhancing future implementations and organizational objectives. Moreover, they developed a checklist CSFs. Based on these arguments, the researcher has carefully selected Acceptability, SI, and TMS as the independent variables of the study.

\section{CMM}

CMM is defined as: A model for judging the maturity of the processes of an organization and for identifying the key practices that are required to increase the maturity of these processes (Becker, Niehaves, Poeppelbuss, \& Simons, 2010). $\mathrm{CMM}$ is a model that is based on actual data. CMM has been originally used in the software development industry by engineers, to improve business procedures in various fields like risk management, information communication and technology, store management, project management, construction engineering and management, software engineering and more (Paulk, 2009). Each process/procedure are ranked according to their intensity on the CMM scale. They then serve as a basis for improving future processes.

CMM Originated from military research funding. The Carnegie-Mellons Software Engineering Institute had a task to produce a model for assessing software engineers from the United States Army (Air Force based) in the 1970s, when the need for the usage of the computer became common and necessary in every establishment, which made the demand in software development to grow. However, because computer engineering was a new field, it lacked a consistent model for evaluating business processes and practices (Mellon, 2016). To solve a problem occurring in the military with software development running over-budget and slower than expected, the study was commissioned (Watts, 2018). Watts Humphrey was admitted into Carnegie-Mellons Institute in 1986, Humphrey was using Process Maturity Framework long before he started with the U.S. Army. (Defense Department). He then combined this framework with a previous study called Quality Management Maturity Grid developed by Philip B Cosby in Quality is Free. What he came up with was an approach demonstrating that an organizations processes mature in stages based upon problems they must solve. This process maturity measurement system became known as the CMM in 1988. Since then, the model has been reworked into The Capability Maturity Model Integration (CMMI), a process improvement methodology providing organizations with a defined structure and practice (Paulk, 2009).

CMM is executed at the assessment stage of the organization to show the level of maturity of the company. These are done in five phases of the CMM, these are the Initial, Repeatable, Defined, Managed, Optimized. The CMM is used whenever a company wants to create predictability and effectiveness in its processes. As the companys processes move from level one to level five, the predictability and effectiveness of the companys processes increase. Each of the aforementioned levels contains five definitions which are Goals, Commitment, Ability, Measurement, and Verification which are also the Key Process Areas (Backlund, Chronéer, \& Sundqvist, 2014). It is also important to note that companies are not to skip any of the levels. Based on the above arguments that organizations need to access their level of maturity and go through the various process in different levels to achieve organizational success in implementing a project, the researcher has used OM as one of the Independent variable (IVs) for this study and PMFs as the mediating factor for the study.

\section{Development of Conceptual Framework/Hypotheses}

Based on the underpinning theories described above and extant academic literature on Project Management and project success, three factors, collectively referred to as Antecedents are derived which are used to develop the conceptual framework. The identified three factors are Acceptability, TMS, and OM.

The conceptual framework comprises of the Independent Variables (IVs), Mediation Variable, Moderation Variable, and the Dependent Variable (DV) as shown in Figure 1. 


\section{Antecedents}

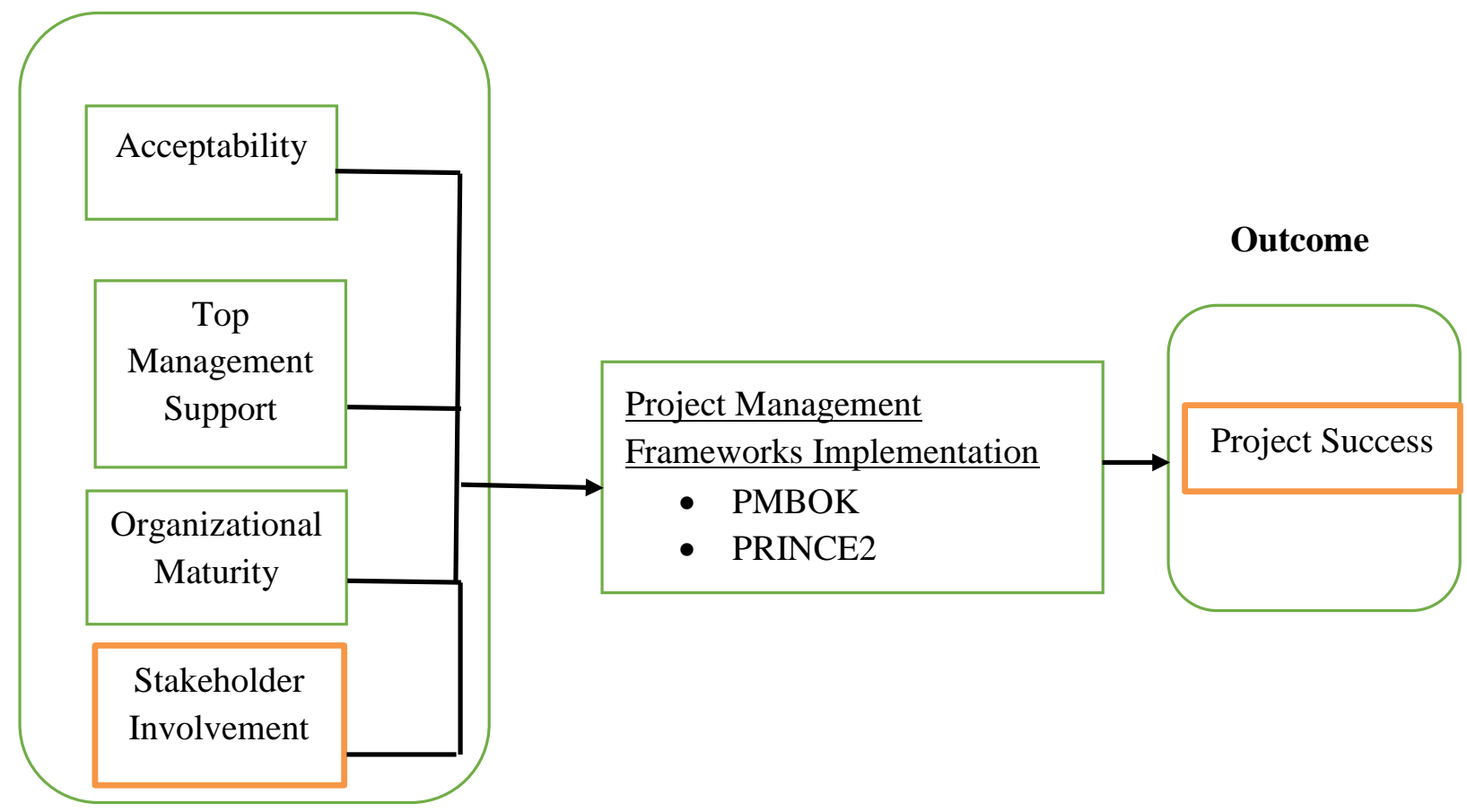

Figure 1 Conceptual Framework for PMFs Implementation and influence on Project Success

Acceptability: Acceptability is the ability to accept and act of acceptance. a commodity will be regarded as acceptable if it is pleasing and satisfaction is derived from the consumption of the commodity (Schade, Schlag, et al., 2000) From a logical perspective, a thing can be said to be acceptable if it has no characteristics that make it unacceptable (Beeby et al., 2009).

The concept of acceptability was developed by Hungarian the mathematician who said acceptability was "taken as a measure of the approximation to the truth" (Schade et al., 2000). This concept was challenged by scholars concerning its applicability to philosophy. Acceptability can also be seen as a point of negotiation where stakeholders will want to negotiate and come to an ideal solution that will benefit or satisfy all parties involved.

In a proposal for projects, there is the need to access if stakeholders will accept the project or not, if after assessment it comes out that the project will be rejected or unacceptable by stakeholders, then it is important to put measures and to identify what is acceptable for users. A project is acceptable if it meets the goals and specifications of users.

Acceptability commences at the senior management level in the organization. Once the framework is accepted at that level, it becomes easier to cascade the framework to the rest of the users. The disadvantage of this approach is the fact that junior employees perceive it as an imposition from the superiors and therefore accept to use the methodology without giving relevance to the project at hand. In the study conducted by Queensland University of Technology (2010), they showed that coaching and mentoring was important to overcome cultural resistance to the introduction of PMF. Acceptability of a PMF also requires a culture change among the employees of the organization. People also need positive reinforcement. The organization needs to offer rewards and recognition (Longman, 2005). Driving culture change requires much more than simply teaching new skills since people have resistance to the change (Mochal, 2002).

Many scholars used acceptability in their research in an attempt to find out if the implementation or adoption of a new product, project, program, etc. is acceptable for consumers and clients alike (Král' \& Janošková, 2015; Pastolero, Suss, \& Hammerschlag, 2019; Selmoune, Cheng, Wang, \& Liu, 2020). Martins (2013) in trying to comprehend the factors of internet banking adoption, endeavored to elucidate the correlation between user believes, intentions and attitudes, came out with the fact that all parties or stakeholders must have one goal and understanding about the project. They must also analyze the real perception and the main reasons for peoples willingness to adopt these technologies.

In their study, they aimed to explore the suitability and acceptability of Lean Construction in Sri Lanka and came 
out with the fact that a test of Acceptability will consider if the strategic option will get vital support from those who are expected to benefit from the project they continued to argue that people will accept and believe in the new philosophies and if they accept its principles and believes that they are true. Their study finally concluded that projects are suitable and acceptable if the workforce is to accept and believe in the core principles. For these reasons, organizations need to investigate this area before implementing any kind of PMFs in other to get maximum benefits (Schlag \& Schade, 2000).

To analyze the reasons why clients may accept or reject a project, many authors have used acceptability or the unified acceptance theory to make this assessment (Beeby et al., 2009; Hachimi \& Salahddine, 2019; Taiwo \& Downe, 2013; Takim, Abdul-Rahman, Ismail, \& Egbu, 2008). Based on these, the researchers came out with the hypothesize that:

H1a: There is a significant relationship between Acceptability and PMFs adoption in terms of using PRINCE2.

H1b: There is a significant relationship between Acceptability and PMFs adoption in terms of using PMBOK.

Stakeholders Involvement (SI): Many stakeholders, individuals, and groups are involved in the provision and delivery of construction projects and each has its role, requirements, and objectives. So, because stakeholders of projects are numerous and different, this introduces a level of complexity to the concept of SI (Bal, Bryde, Fearon, \& Ochieng, 2013). However, depending on the type of project being undertaken and its specific requirements, only certain groups may need to get fully involved in all phases of a project.

To meet the differing demands of different stakeholder groups and to increase the effectiveness and efficiency of the decisions that are made during the project lifecycle, project managers need to develop comprehensive SI plans (Heravitorbati, Coffey, Trigunarsyah, \& Saghatforoush, 2011). Previous studies in the construction sector (Bal et al., 2013; Bosher, Dainty, Carrillo, \& Glass, 2007) highlight that SI is important in improving the effectiveness of project outcomes (Yang, 2010). The quality of a construction project is also largely dependent on the appropriate performance management of diverse stakeholders, especially contractors and consultants. This implies that, if major parties of a contract are not committed to properly carrying out their responsibilities, it is likely to adversely affect the final project quality level.

Bosher et al. (2007) studying stakeholder issues have realized that the activities and practices undertaken by major parties have undeniable impacts on project outcomes. Therefore, identification of the important roles of key members on projects has developed more in recent years.

Based on the above discussions, it is therefore hypothesized that:

H2a: There is a significant relationship between SI and PMFs adoption in terms of using PRINCE2.

H2b: There is a significant relationship between SI and PMFs adoption in terms of using PMBOK.

OM: OM is a progressive evolution of an organization enhancing its workforce, procedures, and skills through the adoption and implementation of good practices (Matt, Modrák, \& Zsifkovits, 2020). OM is about the level of adoption of organizational performance tools by integrating and strengthening internal controls and performance processes coupled with technical and architectural strengths (Odważny, Wojtkowiak, Cyplik, \& Adamczak, 2019). They often measure the people and their values, procedures, and structures then technology (Matt et al., 2020).

According to The Open Group (2017) Maturity is a measurement of the ability of an organization for continuous improvement in a particular discipline. The book continues to say that the higher the maturity, the higher will be the chances that incidents or errors will lead to improvements either in the quality or in the use of the resources of the discipline as implemented by the organization. OM can be looked at using two approaches which are top-down Or bottom-up approach, both approaches occur at different levels of the maturity model and they have very distinct characteristics (The Open Group, 2017).

The level of an organizations maturity provides a way to predict the future performance of the organization within a given discipline or set of disciplines. Experience has shown that organizations do their best when they focus their process-improvement efforts on a manageable number of process areas that require increasingly sophisticated effort as the organization improves (Matt et al., 2020; E. K. Owusu et al., 2019; A. Owusu, Agbemabiasie, Abdurrahaman, \& Soladoye, 2017). It is essential to note that change programs in high maturity organizations almost always succeed.

It is important noting that many scholars have used OM in their work in other to understand where the organization is and when to introduce or implement something new for the organizational benefit (Farrokh \& Mansur, 2013; Gomes \& Romão, 2014; Mettler, 2011; Seelhofer \& Graf, 2018; Spruit \& Pietzka, 2015).

Based on the above discussions, it is therefore hypothesized that:

H3a: There is a significant relationship between OM and PMF adoption in terms of using PRINCE2. 
H3b: There is a significant relationship between $O M$ and PMF implementation in terms of using PMBOK.

TMS: Top Management is the highest-ranking executives of an organization. They use titles like Chair, CEO (chief executive officer), Managing Director, President, Executive Director, etc. They are responsible for translating policies into goals and objectives. Top management decisions affect everybody in the organization and are responsible for the success and failure of the organization (Acheampong \& Moyaid, 2016; Liu et al., 2020; A. Owusu, Agbemabiasie, et al., 2017; A. Owusu, Ghanbari-Baghestan, \& Kalantari, 2017; A. Owusu \& Broni Jr, 2020; Young \& Jordan, 2008; Young \& Poon, 2013). Top Management responsibility goes beyond making decisions that affect the organization but also seek to the interest of its workers and most often also see to the interest of all stakeholders of the organization (Järveläinen, 2020). They also ensures that there is organizational decorum and that the organization presents itself to the public as disciplined and thereby calving a good image for itself to achieve overall organizational objectives (Nguyen \& Nguyen, 2020). Top Management also establishes the corporate culture and sees to it that corporate policies and acceptable behaviors are adhered to, provision of support for asset management and efficient financial decisions also is made by top management top-level management (Liu et al., 2020).

Jitpaiboon and Kalaian (2005), Young and Jordan (2008) noted that, for a framework to be implemented in an organization, there will be a need for the top management to take concrete decisions on how, when, where, etc. the implementation should take place to ensure success. To implement PMFs staff need to be motivated, there will be a cause for change in other to adjust and adapt to the new ways of doing things (Järveläinen, 2020) and thereby the need for Top management commitment and support. There might be the need for resources and strategies to be adjusted in other to fit into the newly adopted framework to be implemented (Hsu, Liu, Tsou, \& Chen, 2019). This role of top management will be the factor that will determine the success or failure when developing and implementing a new framework (Jitpaiboon \& Kalaian, 2005; Young \& Jordan, 2008; Young \& Poon, 2013) attested that TMS is an imperative factor to determine the success or failure when implementing projects.

To ensure management support in the implementation of a framework, top management needs to be the brain behind the initiation of the project charter in other to ensure availability of resources to be committed, assess financial and non-financial impacts of the project to be implemented and validate where necessary challenges that might arise, top management needs to be represented in meetings, forums, training events, etc. meant for the project so as understand the system and be ready with a disaster recovery plan which will also expose them to industry best practices, prepare incentives for staffs to get them willingly embrace the new project (PMFs) implementation. Finally, top management should make available a backup and Succession strategy (Ilyas, Hu, \& Wiwattanakornwong, 2020; Ključnikov, Mura, \& Sklenár, 2019; Nguyen \& Nguyen, 2020; Wijethilake \& Lama, 2019). Therefore, it is necessary to verify through this study if the availability of support from outside experts or consultants, TMS and expert knowledge could be the influential factors of organizations to adopt PMF literature has shown that a lot of scholars has used TMS in their work in the area of adoption and implementation of a project and also prove that TMS is very necessary and cannot be ignored in an organization (Hsu et al., 2019; Ilyas et al., 2020; Järveläinen, 2020; Ključnikov et al., 2019; Liu et al., 2020; Nguyen \& Nguyen, 2020; A. Owusu \& Broni Jr, 2020; A. Owusu, 2019; Khan, Long, \& Iqbal, 2014; Wijethilake \& Lama, 2019; Young \& Jordan, 2008; Young \& Poon, 2013). Based on the above discussions, it is therefore hypothesized that:

H4a: There is a significant relationship between TMS and PMFs implementation in terms of using PRINCE2.

H4b: There is a significant relationship between TMS and PMFs implementation in terms of using PMBOK.

\section{Mediation Variable - PMFs}

Concerning the research model, PMFs implementation acts as a mediation variable. However, theoretically, this was not hypothesized as the researchers focus is on exploring the factors that affect the successful implementation of PMFs and also investigate if the adoption and use of PMFs lead to project success. Thus, the mediation variable is not hypothesized.

\section{Dependent Variable (DV) Project Success}

Radujković and Sjekavica (2017) sees Project Success as the most beloved word of any project practitioner. They argue that there are two main success concepts when talking about projects: project success and project management success, and also brings out the similarities and differences between the two project scopes, they see the main difference to be issued with linking project success and evaluating the overall project goals achievement, they also mentioned 
that project management success relates to traditional measurements of time, cost and quality performance and noted that the existence of many different models for projects and project success has brought about a strong differentiation between them.

Project stakeholders normal set certain criteria for evaluating Project Success, these criteria are to meet the project owners strategic organizational objectives (goal), the satisfaction of users needs (purpose); and satisfaction of stakeholders needs where they relate to the product (primary customer/user) (Abdurrahaman, Owusu, \& Bakare, 2020; Collins \& Baccarini, 2004). The project manager must know project management to ensure project success (Lawani \& Moore, 2016). Radujković and Sjekavica (2017) mentioned that a successful project is one that overcomes its limiting factors which are time, cost, quality, scope, resources, and risks.

It has been established by many project management writers that project success is a vital part of project management implementation and that is why the researcher has used it as the dependent variable (DV) for the work.

Based on the above discussions, it is therefore hypothesized that:

H5a: PMFs adoption in terms of PRINCE2 will have a positive impact on Project Success.

H5b: PMFs adoption in terms of PMBOK will have a positive impact on Project Success.

\section{METHODOLOGY}

This research adopted the postpositivist approach as the researcher began with the review of the literature centered on the underpinning theories from which the study constructs were adapted, and the necessary hypotheses formulated. Data was collected through a survey method with stratified and convenience sampling from 105 project management consultants, contractors, and other key stakeholders involved in project management. The questionnaire comprises of three sections with section one focusing on the respondents demographics. Section two dealt with the IVs whilst the last section asks questions about the dependent variables.

\section{DATA ANALYSIS}

\section{Respondents Demographics}

In all, 105 responses were received. These respondents came from a varied array of industries including Agriculture, Banking, Construction, Health, Education, Legislature, Aviation, Manufacturing, Electrical/Electronics, Services, Catering, and Food.

Table 1 DEMOGRAPHIC PROFILE OF RESPONDENTS

\begin{tabular}{|c|c|c|c|}
\hline Variable & Item & Frequency & Percentage \\
\hline \multirow[t]{2}{*}{ Gender } & Male & 85 & 80.95 \\
\hline & Female & 20 & 19.1 \\
\hline \multirow{6}{*}{ Age } & Below 20 & 0 & 0 \\
\hline & $20-29$ & 20 & 19.1 \\
\hline & $30-39$ & 30 & 28.5 \\
\hline & $40-49$ & 35 & 33.3 \\
\hline & $50-59$ & 20 & 19.1 \\
\hline & $60+$ & 0 & 0 \\
\hline \multirow[t]{5}{*}{ Educational Level } & Diploma HND & 05 & 04.7 \\
\hline & Bachelor & 75 & 71.5 \\
\hline & Masters & 20 & 19.1 \\
\hline & $\mathrm{PhD}$ & 5 & 4.7 \\
\hline & Professional & 0 & 0 \\
\hline
\end{tabular}


TABLE 1 CONTINUE

\begin{tabular}{llll}
\hline \multirow{2}{*}{ Variable } & Item & Frequency & Percentage \\
\hline \multirow{3}{*}{ Experience } & 1 to 3 years & 35 & 33.3 \\
& 4 to 10 years & 55 & 52.4 \\
Role in the organization & More than 10 years & 15 & 14.3 \\
& Manager of Project Managers & 10 & 9.5 \\
& Project Manager & 60 & 57.1 \\
& Subordinate Manager & 5 & 4.8 \\
& Functional Manager & 10 & 9.5 \\
& Architect & 5 & 4.8 \\
& Estate Manager & 15 & 14.3 \\
& Agriculture & 20 & 19.1 \\
& Banking & 25 & 23.8 \\
& Construction & 10 & 9.5 \\
& Health & 40 & 38.2 \\
& Education & 5 & 4.7 \\
& Legislature & 0 & 0 \\
& Aviation & 0 & 0 \\
& Manufacturing & 5 & 4.7 \\
\hline
\end{tabular}

Table 1 shows the demographic profile of the respondents. $80.95 \%$ of the respondents were males with females forming $19.1 \%$. Regarding the Age distribution of the respondents, $33.3 \%$ of the respondents were found in the 40-49 age categories followed by $28.5 \%$ who were found in the $30-39$ age categories. Concerning the Level of Education, the majority of the respondents had a Bachelors degree representing 71.5\%. This is followed by those with a Masters degree representing 19.1\%. Regarding the Level of Experience of respondents, 52.4\% of the respondents have between 4 to 10 years experience followed by $33.3 \%$ with 1 to 3 years experience. In terms of the Roles respondents play in their respective organizations, 57.1\% of the respondents are Project Managers with 14.3\% being Estate Managers. Lastly, in terms of the Sectors, the majority of the respondents were found in the Health sector with $38.2 \%$ followed by Banking with $23.8 \%$.

\section{Inferential Statistics}

The collected data were subjected to Structural Equation Modeling (SEM) through the partial least squares approach where the 2-step approach of analyzing data in SEM was employed. First, the measurement model was assessed and then the structural model was also evaluated (Hair Jr, Hult, Ringle, \& Sarstedt, 2016). SmartPLS 3.2.9 (Ringle, Wende, \& Becker, 2015) was used to assess both the measurement and structural models.

Assessing the Measurement Model: Reliability and Validity Test- According to (Creswell, 2014), Reliability denotes that scores from an instrument are stable and consistent. Also, Thornhill, Saunders, and Lewis (2009) defined reliability as the extent to which your data collection techniques or analysis procedures will yield consistent findings. Furthermore, Creswell (2014) asserted that the validity and reliability of scores on instruments are prime to meaningful interpretations of data.

Reliability comes in various forms. One form is internal consistency which is computed by calculating the Cronbachs alpha (Hair Jr et al., 2016; Thornhill et al., 2009). Also, Cronbachs alpha measures the degree to which the items used are internally reliable with other items including the construct. This takes values ranging from 1 (which indicates the items correlate perfectly) and 0 (which denotes the items are totally inconsistent). An alpha score of above 0.70 indicated internal consistency and was considered reliable (Nunnally, 1978). 


\begin{tabular}{|c|c|c|c|c|c|}
\hline Constructs & Indicators & Outer Loadings & Cronbach's Alpha & $\begin{array}{l}\text { Composite } \\
\text { Reliability }\end{array}$ & $\begin{array}{l}\text { Average Variance Ex- } \\
\text { tracted (AVE) }\end{array}$ \\
\hline \multirow[t]{3}{*}{ Acceptability } & Acceptability 1 & 0.705 & 0.709 & 0.837 & 0.635 \\
\hline & Acceptability 2 & 0.935 & & & \\
\hline & Acceptability3 & 0.731 & & & \\
\hline \multirow[t]{5}{*}{$\mathrm{OM}$} & OM1 & 0.854 & 0.860 & 0.892 & 0.624 \\
\hline & $\mathrm{OM} 2$ & 0.853 & & & \\
\hline & OM3 & 0.684 & & & \\
\hline & OM4 & 0.786 & & & \\
\hline & OM5 & 0.761 & & & \\
\hline \multirow[t]{5}{*}{ PMFs } & PMFs1 & 0.781 & 0.787 & 0.855 & 0.546 \\
\hline & PMFs2 & 0.824 & & & \\
\hline & PMFs3 & 0.684 & & & \\
\hline & PMFs4 & 0.786 & & & \\
\hline & PMFs5 & 0.761 & & & \\
\hline \multirow[t]{7}{*}{ SF } & $\mathrm{SF} 1$ & 0.785 & 0.845 & 0.880 & 0.514 \\
\hline & SF14 & 0.704 & & & \\
\hline & SF17 & 0.683 & & & \\
\hline & SF5 & 0.657 & & & \\
\hline & SF6 & 0.788 & & & \\
\hline & SF7 & 0.722 & & & \\
\hline & SF9 & 0.666 & & & \\
\hline \multirow[t]{3}{*}{ SI } & SI1 & 0.880 & 0.871 & 0.920 & 0.794 \\
\hline & SI2 & 0.887 & & & \\
\hline & SI3 & 0.907 & & & \\
\hline \multirow[t]{4}{*}{ TMS } & TMS1 & 0.831 & 0.798 & 0.870 & 0.628 \\
\hline & TMS2 & 0.839 & & & \\
\hline & TMS3 & 0.829 & & & \\
\hline & TMS4 & 0.656 & & & \\
\hline
\end{tabular}

Note: $\mathrm{OM}=$ Organizational Maturity; PMFs = Project Management Frameworks; SF = Success Factors; SI = Stakeholder Involvement; TMS = Top Management Support

The reliability test for this studys instrument was assessed through both Cronbachs alpha value as well as the composite reliability (Hair Jr et al., 2016). The data was also subjected to Confirmatory Factor Analysis (CFA) to get insights as to the multidimensionality of the items using SmartPLS 3.2.9 (Ringle et al., 2015) and discriminant validity test. Cronbach alpha value provides an estimate of the reliability based on the intercorrelations of the observed indicator variables (Hair Jr et al., 2016). Cronbachs alpha has a weakness of assuming all the indicators are equally reliable (that is all the indicators have equal outer loadings on the construct) and it is also sensitive to the number of items in the scale and generally tends to underestimate the internal consistency reliability (Hair Jr et al., 2016). However, composite reliability takes into account the different outer loadings of the indicator variables (Hair Jr et al., 2016) and thus ensures more reliability on each construct.

Table 2 shows the summary measurement model with the Cronbach Alpha, Composite Reliability, and the AVE values of all the constructs. As shown in Table 2, the test results indicate that all the latent variables meet the Cronbach alpha value of 0.7 or higher (Nunally, 1978), which is the acceptable value for reliability. Also, the results indicate that all the measures are robust in terms of their internal consistency reliability which is shown by the composite reliability. The composite reliabilities values of the different measures in the model range from 0.837 to 0.920 which well exceeds the recommended value of 0.7 as shown in Table 2. Also, from Table 2, all the AVE values are well above 0.5. This 
shows that all the indicators for each construct converge very well to form the constructs (Hair Jr et al., 2016).

Again, from Table 2, the confirmatory factor analysis shows acceptable factor loading on the hypothesized measurements. The outer loadings of most of the indicators meet the acceptable value of 0.7 or higher which is recommended for indicator reliability with very few falling below 0.7 . However, these indicators were maintained as (Wong, 2013) has recommended values of 0.4 or higher for exploratory research. The indicators below 0.7 have their values ranging from 0.656 to 0.683 and hence they were maintained. However, the outer loadings SF2, SF3, SF4, SF8, SF10, SF11, SF12, SF13, SF15, SF16, SF18, SF19, SF20, and SF21 have very low outer loadings. As a result, they were all deleted.

Construct validity ensures if the items measure hypothetical constructs or concepts as designed (Creswell, 2014). This has become very useful in recent studies and has focused on whether the scores serve a useful purpose and have positive consequences when they are used in practice. Also, Creswell (2014) asserted that establishing the validity of the scores in a survey helps to identify whether an instrument might be a good one to use in survey research.

After the reliability test, the next analysis was to check the validity of the measures. This was done through the discriminant validity through the Fornell-Larcker criteria.

From Table 3, all the constructs meet the satisfactory values for discriminant validity based on the Fornell-Larcker Criterion (Fornell \& Larcker, 1981; Hair Jr et al., 2016), as the square root of each construct's AVE is greater than its highest correlation with any other construct.

Table 3 DISCRIMINANT VALIDITY - FORNELL-LARCKER CRITERION

\begin{tabular}{lllllll}
\hline Constructs & $\begin{array}{l}\text { Acceptabil- } \\
\text { ity }\end{array}$ & OM & PMFs & SF & SI & TMS \\
\hline Acceptability & 0.797 & & & & & \\
OM & 0.611 & 0.790 & & & & \\
PMFs & 0.578 & 0.412 & 0.739 & & & \\
SF & -0.202 & -0.095 & -0.339 & 0.717 & & \\
SI & 0.608 & 0.542 & 0.564 & -0.075 & 0.891 & 0.793 \\
TMS & 0.504 & 0.357 & 0.567 & -0.354 & 0.445 & \\
\hline
\end{tabular}

Note: $\mathrm{OM}=$ Organizational Maturity; PMFs = Project Management Frameworks; SF = Success Factors; SI = Stakeholder Involvement;

TMS = Top Management Support.

Assessing the Structural Model: After determining that the measurement model satisfies all the acceptable values, the next stage is to evaluate the structural model.

Hypotheses testing- The bootstrapping technique was adopted for the testing of the hypotheses. SmartPLS 3.2.9 creates the $t$-value which provides the statistical significance of the causal path between the constructs in the hypothesized model. Hair Jr et al. (2016) stated that for a two-tailed test, the popular critical $t$-values in PLS-SEM are $1.65(\alpha=$ $0.10), 1.96(\alpha=0.05)$, or $2.57(\alpha=0.01)$.

Results from the bootstrapping technique for the Structural Model signifying the $t$-values causal links amongst the latent variables are shown in Figure 2 and Table 4, respectively. At 5\% significance level ( $t$-value 1.96), SI-> PMFs $(t$ $=1.992, p=0.046)$, TMS $->$ PMFs $(t=15.173, p=0.000)$ emerged significant. Therefore, hypotheses H2a, H2b, H4a, and $\mathrm{H} 4 \mathrm{~b}$ are accepted.

However, Acceptability $\rightarrow$ PMFs $(t=1.338, p=0.181)$, OM $\rightarrow$ PMFs $(t=0.676, p=0.499)$, and PMFs $\rightarrow$ SF $(t=$ 1.282, $p=0.200$ ) did not appear significant. Therefore, hypotheses H1a, H1b, H3a, H3b, H5a and H5b are all rejected. 


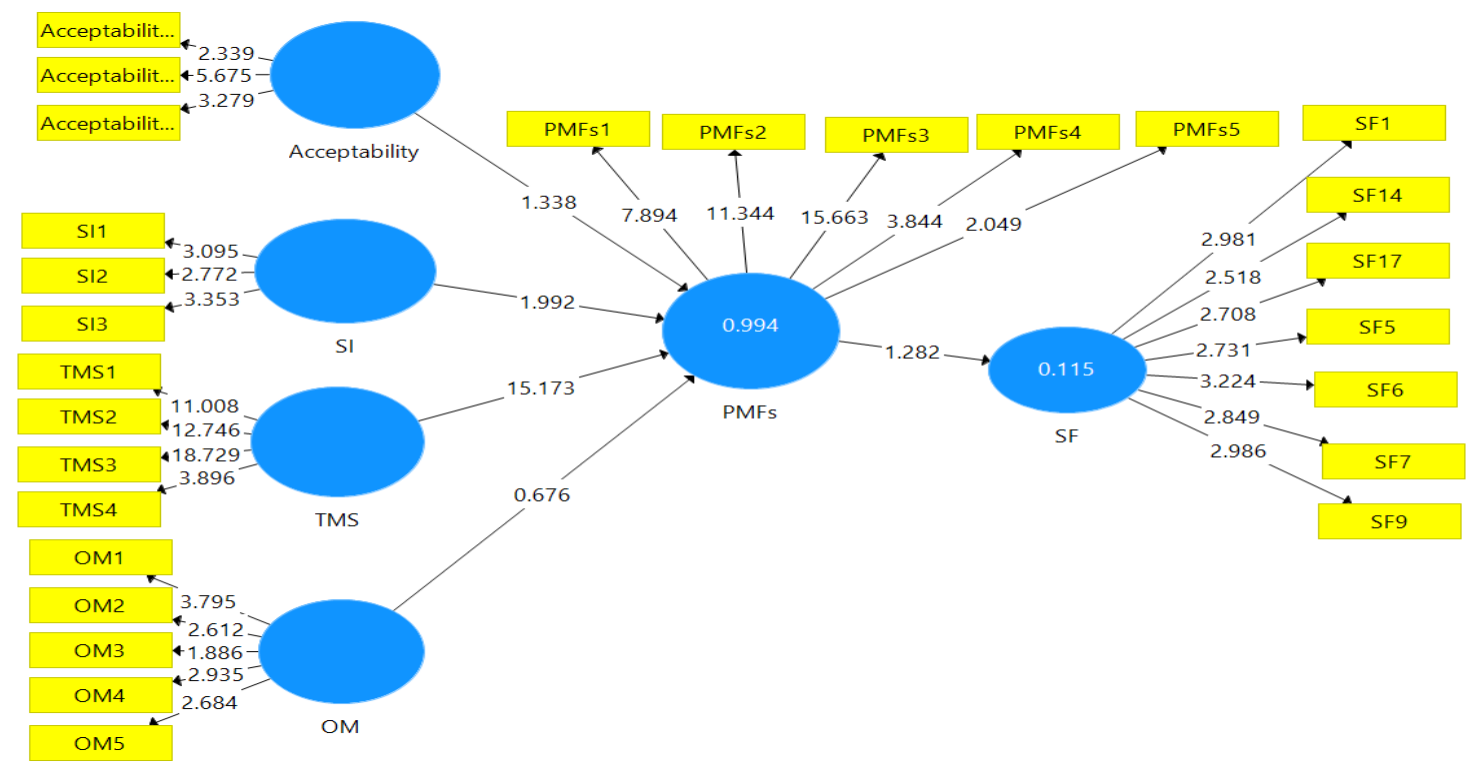

Figure 2 Bootstrapping Results from the Structural Model

Table 4 TEST OF HYPOTHESES

\begin{tabular}{lllll}
\hline Paths & Hypothesis & $\beta$-value & $t$-values & Supported? \\
\hline & & & & \\
Acceptability $->$ PMFs & H1a, H1b & 0.045 & 1.338 & No \\
SI-> PMFs & H2a, H2b & 0.142 & 1.992 & Yes \\
OM -> PMFs & H3a, H3b & -0.017 & 0.676 & No \\
TMS -> PMFs & H4a, H4b & 0.907 & 15.173 & Yes \\
PMFs -> SF & H5a, H5b & -0.339 & 1.282 & No \\
\hline
\end{tabular}

Table $5 R^{2}, R^{2}$ ADJUSTED, $F^{2}$ AND $Q^{2}$ VALUES

\begin{tabular}{lllll}
\hline Constructs & $R^{2}$ & $R^{2}$ Adjusted & $f^{2}$ & $Q^{2}$ \\
\hline Acceptability & - & - & 0.595 & - \\
SI & - & - & 0.570 & - \\
OM & - & - & 0.222 & - \\
TMS & - & - & 0.075 & - \\
PMFs & 0.994 & 0.993 & - & 0.462 \\
SF & 0.115 & 0.082 & - & 0.031 \\
\hline
\end{tabular}

The coefficient of determination - $R$ square-The coefficient of determination is denoted as the $R^{2}$ value and it measures the models predictive accuracy in PLS-SEM. The $R^{2}$ value is computed as the squared correlation between a specific endogenous constructs actual and predicted value. The $R^{2}$ value is the representation of all the exogenous latent variables collective effects on the endogenous construct. It is also the amount of the variance in the endogenous constructs which is explained by all of the exogenous constructs linked to it (Hair Jr et al., 2016). The $R^{2}$ value has a rule of thumb with values ranging from 0 to 1 . Values of $0.75,0.50$, or 0.25 for endogenous latent variables have been specified as substantial, moderate, or weak, respectively (Hair Jr et al., 2016).

From Table 5, the $R^{2}$ values of 0.995 and 0.115 indicate that the combined effects of exogenous latent variables Acceptability, SI, OM, and TMS explain $99.5 \%$ of the variance of the endogenous construct PMFs. Similarly, the 
endogenous latent variable PMFs explains $11.5 \%$ of the Project Success construct.

Effect sizes-The effect size is denoted as $f^{2}$ and is used to measure an exogenous latent variables influence on an endogenous constructs $R^{2}$ value. The $f^{2}$ value is used by scholars to assess the importance of individual latent variables contribution in explaining the variance of the endogenous constructs. The rule of thumb for $f^{2}$ values ranges from $0.02,0.15$ and 0.35 indicating an exogenous constructs small, medium or large effect, respectively, on an endogenous construct (Hair Jr et al., 2016).

From Table 5, with an $f^{2}$ values of 0.595 and 0.570, it emerged that Acceptability has the highest effect size on PMFs construct followed by SI. Also, with an $f^{2}$ value of 0.222 , OM has a medium effect on PMFs. However, it emerged that TMS has a small effect size on the PMFs implementation.

Models predictive relevance- The predictive relevance of the model was assessed through the StoneGeissers $Q^{2}$ value (Geisser, 1974; Stone, 1974). This study followed the blindfolding procedure via the cross-validated redundancy approach as recommended by (Hair Jr et al., 2016), to calculate the $Q^{2}$ value. From Table 5, the $Q^{2}$ value of 0.462 and 0.031 indicates the structural path model has predictive relevance.

\section{DISCUSSION}

This study seeks to find factors influencing the implementation of PMFs and if the implementation of PMFs leads to project success.

From the analysis, the hypothesized relationships between SI and TMS were found to influence the adoption of PMFs. However, the hypothesized relationships between Acceptability and OM does not influence the adoption of PMFs. Moreover, PMFs does not influence Project Success. The findings are discussed below.

\section{SI}

Stakeholders are found to be highly beneficial when it comes to the success of every project. Thus, it is not surprising that their involvement emerges significantly in this preliminary study. Having key SI in projects has proven to be a highly influencing project success (Bal et al., 2013). Thus, this study corroborates others that found SI to influence project success (Yang, 2010).

\section{TMS}

The support from Top Management is key to the success of every project in organizations as they approve such projects and also give their consent for funding (A. Owusu, Agbemabiasie, et al., 2017; Wijethilake \& Lama, 2019; Young \& Jordan, 2008). Thus, this study corroborates several others that have found TMS as a key factor influencing PMFs implementation (Hsu et al., 2019; Ilyas et al., 2020; Järveläinen, 2020; Ključnikov et al., 2019; Liu et al., 2020; Nguyen \& Nguyen, 2020; A. Owusu \& Broni Jr, 2020; Khan et al., 2014; Young \& Poon, 2013).

\section{Acceptability}

Contrary to several studies Uma et al., 2019; (Beeby et al., 2009; Hachimi \& Salahddine, 2019, 2019; Takim et al., 2008) that have found acceptability to influence the implementation of PMFs, this preliminary study proves otherwise. The findings emerge that acceptability does not influence PMFs implementation. This may be due to the fact that most of the consultants, contractors, and other key stakeholders surveyed find PMFs (PMBOK and PRINCE2) as cumbersome and thereby want to have their approach of supervising their projects.

\section{$O M$}

OM also emerges insignificant in this preliminary study and does not influence the implementation of PMFs. This may be due to the fact that the organizations surveyed may not have the requisite resources and thus do not see the need for implementing PMFs. The insignificance of OM in this study corroborates other (Farrokh \& Mansur, 2013; Gomes \& Romão, 2014; Mettler, 2011; Spruit \& Pietzka, 2015) Seelhofer \& Graf, 2018; .

\section{PMFS}

Contrary to the belief that the implementation of the PMFs will influence the success of projects, this preliminary study proves otherwise. This is quite surprising as the literature points out that the implementation of best practices and methodologies such as PMBOK and PRINCE2 will lead to the success of projects (Bakare, Owusu, \& Abdurrahaman, 
2017; Radujković \& Sjekavica, 2017). This factor emerging insignificant in this study may be due to the fact that most of the various consultants, contractors the stakeholders surveyed have not be been using these methodologies for their work and thus do not know their benefits. The findings are contrary to the others that found PMFs implementation leading to project success (Lawani \& Moore, 2016; A. Owusu, 2019, 2017; Radujković \& Sjekavica, 2017).

\section{CONCLUSION, RECOMMENDATIONS, AND SUGGESTIONS FOR FUTURE STUDIES}

This study developed a conceptual framework grounded on the CSFs and CMM theories to examine the factors that affect PMFs adoption in Ghana. The model was also used to determine if the adoption of PMFs leads to project success in Ghana.

The findings indicate that PMFs implementation is influenced by SI and TMS. However, Acceptability and OM does not influence the implementation of PMFs. Moreover, PMFs implementation does not lead to project success.

The study was necessitated by the fact that many projects in Ghana are failing and as there is little literature regarding PMFs in the Ghanaian context, the researchers sought to explore if best practices are adhered to by Project Management consultants and contractors.

This study contributes to the body of knowledge theoretically by developing a conceptual framework grounded on two theories and empirically testing the framework with primary data to confirm or reject the hypotheses. Thus, the study has enriched the project management literature with empirical evidence also coming from a developing country, Ghana.

In terms of contributions to policy and practice, this study though preliminary has given us enough insights as to what factors policymakers should focus on when it comes to the implementation of PMFs. Practically, key stakeholders should encourage project management consultants and contractors to accept the PMFs which when adhered to, will lead to project success which is contrary to what this study found.

In terms of limitations, this study is a preliminary one. Thus, only 105 project management consultants and contractors were surveyed. As such, the findings cannot be generalized to be a true reflection of the Ghanaian context. Future studies should survey a large sample of the key stakeholders that will be a true representation of the Ghanaian context. Future studies can also interview selected key stakeholders to get an in-depth understanding of PMFs implementation in Ghana.

\section{REFERENCES}

Abdul-Aziz, A.-R., \& Kassim, P. J. (2011). Objectives, success and failure factors of housing public-private partnerships in Malaysia. Habitat International, 35(1), 150-157. doi:https://doi.org/10.1016/j.habitatint.2010.06.005

Abdurrahaman, D. T., Owusu, A., \& Bakare, A. S. (2020). Evaluating factors affecting user satisfaction in university Enterprise Content Management (ECM) systems. The Electronic Journal of Information Systems Evaluation, 23(1), 1-16. doi:https://doi.org/10.34190/EJISE.20.23.1.001

Acheampong, O., \& Moyaid, S. A. (2016). An integrated model for determining business intelligence systems adoption and post-adoption benefits in banking sector. Journal of Administrative and Business Studies, 2(2), 84-100. doi:https://doi.org/10.20474/jabs-2.2.4

Ahlemann, F., Teuteberg, F., \& Vogelsang, K. (2009). Project management standards-diffusion and application in Germany and Switzerland. International Journal of Project Management, 27(3), 292-303. doi:https://doi.org/ 10.1016/j.ijproman.2008.01.009

Alreemy, Z., Chang, V., Walters, R., \& Wills, G. (2016). Critical Success Factors (CSFs) for Information Technology Governance (ITG). International Journal of Information Management, 36(6), 907-916. doi:https://doi.org/ 10.1016/j.ijinfomgt.2016.05.017

Amponsah, R., \& Darmoe, J. (2014). A study of the critical success factors influencing projects in the Ghana public sector. The International Journal of Business \& Management, 2(5), 120.

Backlund, F., Chronéer, D., \& Sundqvist, E. (2014). Project management maturity models-a critical review: A case study within swedish engineering and construction organizations. Procedia-Social and Behavioral Sciences, 119(0), 837-846. doi:https://doi.org/10.1016/j.sbspro.2014.03.094

Bakare, A. S., Owusu, A., \& Abdurrahaman, D. T. (2017). The behavior response of the Nigerian youths toward mobile advertising: An examination of the influence of values, attitudes and culture. Cogent Business \& Management, 4(1). doi:https://doi.org/10.1080/23311975.2017.1353231 
Bal, M., Bryde, D., Fearon, D., \& Ochieng, E. (2013). Stakeholder engagement: Achieving sustainability in the construction sector. Sustainability, 5(2), 695-710. doi:https://doi.org/10.3390/su5020695

Banica, L., Radulescu, M., Rosca, D., \& Hagiu, A. (2017). Is devops another project management methodology? Informatica Economica, 21(3), 39. doi:https://doi.org/10.12948/issn14531305/21.3.2017.04

Becker, J., Niehaves, B., Poeppelbuss, J., \& Simons, A. (2010). Maturity models in is research. In ECIS 2010 Proceedings, Pretoria, South Africa.

Beeby, A., Fernández, M., Fox, O., Albir, A., Kozlova, I., Kuznik, A., ... Wimmer, S. (2009). Results of the validation of the PACTE translation competence model: Acceptability and decision making. Across Languages and Cultures, 10(2), 207-230. doi:https://doi.org/10.1556/Acr.10.2009.2.3

Bosher, L., Dainty, A., Carrillo, P., \& Glass, J. (2007). Built-in resilience to disasters: A pre-emptive approach. Engineering, Construction and Architectural Management, 14(5), 434-446. doi:https://doi.org/10.1108/ 09699980710780746

Collins, A., \& Baccarini, D. (2004). Project successa survey. Journal of Construction Research, 5(02), $211-231$. doi:https://doi.org/10.1142/S1609945104000152

Creswell, J. W. (2014). Research design: Qualitative, quantitative and mixed method approaches. Los Angeles, CA: Sage Publications.

Farrokh, J., \& Mansur, A. K. (2013). Project management maturity models and organizational project management maturity model (opm3ß): A critical morphological evaluation. Project Management, 2(7), 23-33.

Ferreira, D., Ferreira, M. A., \& Mariano, B. (2018). Creditor control rights and board independence. The Journal of Finance, 73(5), 2385-2423. doi:https://doi.org/10.1111/jofi.12692

Fornell, C., \& Larcker, D. F. (1981). Structural equation models with unobservable variables and measurement error: Algebra and statistics. Los Angeles, CA: Sage Publications. doi:https://doi.org/10.2307/3150980

Foss, N. J., \& Pedersen, T. (2019). Microfoundations in international management research: The case of knowledge sharing in multinational corporations. Journal of International Business Studies, 50(9), 1594-1621. doi:https:// doi.org/10.1057/s41267-019-00270-4

Geisser, S. (1974). A predictive approach to the random effect model. Biometrika, 61(1), 101-107. doi:https://doi.org/ 10.1093/biomet/61.1.101

Gomes, J., \& Romão, M. (2014). How organizational maturity and project management can cooperate for project success. Faro, Portugal: UALg ESGHT.

Grisham, T. W. (2009). International project management: Leadership in complex environments. New York, NY: John Wiley \& Sons.

Hachimi, A., \& Salahddine, M. M. A. (2019). The acceptability of participatory banking products by SMES: A conceptual framework. International Journal of Economics and Financial Issues, 9(4), 259. doi:https://doi.org/ 10.32479/ijefi.8227

Hair Jr, J. F., Hult, G. T. M., Ringle, C., \& Sarstedt, M. (2016). A primer on Partial Least Squares Structural Equation Modeling (PLS-SEM). Thousand Oaks, CA: Sage publications. doi:https://doi.org/10.1108/EBR-10-2013-0128

Heravitorbati, A., Coffey, V., Trigunarsyah, B., \& Saghatforoush, E. (2011). Evaluating the influences of stakeholder management on construction project quality. In Proceedings of 1st International Construction Business \& Management Symposium, Kuala Lumpur, Malaysia.

Hsu, H.-Y., Liu, F.-H., Tsou, H.-T., \& Chen, L.-J. (2019). Openness of technology adoption, top management support and service innovation: A social innovation perspective. Journal of Business \& Industrial Marketing, 34(3), 575-590. doi:https://doi.org/10.1108/JBIM-03-2017-0068

Hu, J., \& Gao, S. (2019). Research and application of capability maturity model for chinese intelligent manufacturing. Procedia CIRP, 83, 794-799. doi:https://doi.org/10.1016/j.procir.2019.05.013

Ilyas, S., Hu, Z., \& Wiwattanakornwong, K. (2020). Unleashing the role of top management and government support in green supply chain management and sustainable development goals. Environmental Science and Pollution Research, 27(8), 8210-8223. doi:https://doi.org/10.1007/s11356-019-07268-3

Iqbal, J., Khan, M., \& Minhas, N. M. (2018). Are project managers informally following capability maturity model integration practices for project management? Global Journal of Information Technology: Emerging Technologies, 8(3), 86-94. doi:https://doi.org/10.18844/gjit.v8i3.4048 
Järveläinen, J. (2020). Understanding the stakeholder roles in business continuity management practices-a study in public sector. In Proceedings of the 53rd Hawaii International Conference on System Sciences, Hawaii, Manoa. doi:https://doi.org/10.24251/HICSS.2020.241

Jitpaiboon, T., \& Kalaian, S. A. (2005). Analyzing the effect of top management support on Information System (IS) performance across organizations and industries using hierarchical linear modeling. Journal of International Information Management, 14(2), 131-144.

Kerzner, H. (2009). Project management 10th ed+ student workbook+ case studies. New York, NY: John Wiley.

Khan, S. U. R., Long, C. S., \& Iqbal, S. M. J. (2014). Top management support, a potential moderator between project leadership and project success: A theoretical framework. Research Journal of Applied Sciences, Engineering and Technology, 8(11), 1373-1376. doi:https://doi.org/10.1016/j.conctc.2020.100569

Ključnikov, A., Mura, L., \& Sklenár, D. (2019). Information security management in SMEs: factors of success. Entrepreneurship and Sustainability Issues, 6(4), 2081-2094. doi:http://doi.org/10.9770/jesi.2019.6.4(37)

Košt'álová, J., \& Tetřevová, L. (2018). Proposal and verification of project management methods and tools oriented maturity model. Revista de Gestão e Projetos, 9(1). doi:https://doi.org/10.5585/gep.v9i1.595

Král', P., \& Janošková, K. (2015). Condition of acceptability of project risk in management of the project portfolio. Globalization and its Socio-Economic Consequences, 7, 345-352.

Kwofie, E. T. (2015). Contribution of unique features of mass housing projects to project team communication performance. Phd thesis, University of Science and Technology, Kumasi, Ghana.

Lawani, A., \& Moore, D. (2016). Project management practices in government organizations of developing countries: A systematic review. International Journal of Business \& Management, 4(9), 89-98.

Liu, J., Liu, Y., \& Yang, L. (2020). Uncovering the influence mechanism between top management support and green procurement: The effect of green training. Journal of Cleaner Production, 251, 1-12. doi:https://doi.org/ 10.1016/j.jclepro.2019.119674

Liu, J., Love, P. E., Smith, J., Regan, M., \& Davis, P. R. (2015). Life cycle critical success factors for public-private partnership infrastructure projects. Journal of Management in Engineering, 31(5), 04014073.

Longman, . M. J., A. (2005). The rational project manager: A thinking team's guide to getting work done. New York, NY: John Wiley \& Sons.

Martins, A. C. B. (2013). Understanding the internet banking adoption by portuguese customers-a unified theory of acceptance and use of technology and perceived risk application. (PhD dissertation). Universidade NOVA de Lisboa, Lisbon, Portugal.

Matt, D. T., Modrák, V., \& Zsifkovits, H. (2020). Industry 4.0 for SMEs: Challenges, opportunities and requirements. The Hague, Netherlands: Springer Nature. doi:https://doi.org/10.1007/978-3-030-25425-4

Maylor, H., Brady, T., Cooke-Davies, T., \& Hodgson, D. (2006). From projectification to programmification. International Journal of Project Management, 24(8), 663-674. doi:https://doi.org/10.1016/j.ijproman.2006.09 .014

Mellon, C. (2016). Cmmi brief history. Retrieved from https://bit.ly/3kBaKCy

Mettler, T. (2011). Maturity assessment models: A design science research approach. International Journal of Society Systems Science, 3(1-2), 81-98. doi:https://doi.org/10.1504/IJSSS.2011.038934

Mochal, T. (2002). Are project management skills valuable? Tech Republic, 1-2. doi:https://doi.org/10.1007/ 978-1-4302-0820-4_1

Muriithi, N., \& Crawford, L. (2003). Approaches to project management in Africa: Implications for international development projects. International Journal of Project Management, 21(5), 309-319. doi:https://doi.org/ 10.1016/S0263-7863(02)00048-0

Ng, S. T., Wong, Y. M., \& Wong, J. M. (2012). Factors influencing the success of PPP at feasibility stage-A tripartite comparison study in Hong Kong. Habitat International, 36(4), 423-432. doi:https://doi.org/10.1016/ j.habitatint.2012.02.002

Nguyen, H., \& Nguyen, A. (2020). Determinants of accounting information systems quality: Empirical evidence from Vietnam. Accounting, 6(2), 185-198. doi:https://doi.org/10.5267/j.ac.2019.10.004

Nishant, R., Srivastava, S. C., \& Bahli, B. (2020). Does virtualization capability maturity influence information systems development performance? Theorizing the non-linear payoffs. In Proceedings of the 53rd Hawaii International Conference on System Sciences, Hawaii, Manoa. doi:https://doi.org/10.24251/HICSS.2020.677 
Nunnally, J. (1978). Psychometric methods. New York, NY: McGraw-Hill.

Odważny, F., Wojtkowiak, D., Cyplik, P., \& Adamczak, M. (2019). Concept for measuring organizational maturity supporting sustainable development goals. Log Forum, 15(2), 237-247. doi:https://doi.org/10.17270/J.LOG .2019 .321

Ofori, D., \& Deffor, E. W. (2013). Assessing project management maturity in Africa: A Ghanaian perspective. International Journal of Business Administration, 4(6), 41. doi:https://doi.org/10.5430/ijba.v4n6p41

Osei-Kyei, R., \& Chan, A. P. (2015). Review of studies on the critical success factors for Public-Private Partnership (PPP) projects from 1990 to 2013. International Journal of Project Management, 33(6), 1335-1346. doi:https:// doi.org/10.1016/j.ijproman.2015.02.008

Owusu, A. (2017). Business intelligence systems and bank performance in Ghana: The balanced scorecard approach. Cogent Business \& Management, 4(1), 1364056.

Owusu, A. (2019). Examining the moderating effects of time-since-adoption on the nexus between business intelligence systems and organisational performance: The Ghanaian banks perspectives. International Journal of Technology Diffusion (IJTD), 10(3), 49-68. doi:https://doi.org/10.4018/IJTD.2019070104

Owusu, A., Agbemabiasie, G. C., Abdurrahaman, D. T., \& Soladoye, B. A. (2017). Determinants of business intelligence systems adoption in developing countries: An empirical analysis from Ghanaian banks. The Journal of Internet Banking and Commerce, 1-25.

Owusu, A., \& Broni Jr, F. E. (2020). Strategic Information Systems Planning (SISP) implementation and use in a developing economy: The case of Ghanaian organizations. In Handbook of research on managing information systems in developing economies (pp. 1-27). Pennsylvania, PA: IGI Global. doi:https://doi.org/10.4018/ 978-1-7998-2610-1.ch001

Owusu, A., Ghanbari-Baghestan, A., \& Kalantari, A. (2017). Investigating the factors affecting business intelligence systems adoption: A case study of private universities in Malaysia. International Journal of Technology Diffusion (IJTD), 8(2), 1-25. doi:https://doi.org/10.4018/IJTD.2017040101

Owusu, E. K., Chan, A. P., DeGraft, O.-M., Ameyaw, E. E., \& Robert, O.-K. (2019). Contemporary review of anti-corruption measures in construction project management. Project Management Journal, 50(1), 40-56. doi:https://doi.org/10.1177/8756972818808983

Pastolero, P., Suss, A., \& Hammerschlag, M. (2019). P395 acceptability of point of care testing for chlamydia trachomatis in adolescents: If we make it, will they take it? London, UK: BMJ Publishing Group Ltd.

Paulk, M. C. (2009). A history of the capability maturity model for software. ASQ Software Quality Professional, 12(1), 5-19.

Project Management Institute. (2000). A guide to the project management body of knowledge. Newtown Square, PA: Project Management Institute.

Radujković, M., \& Sjekavica, M. (2017). Project management success factors. Procedia Engineering, 196, 607-615. doi:https://doi.org/10.1016/j.proeng.2017.08.048

Ringle, C. M., Wende, S., \& Becker, J. M. (2015). Smartpls 3. Retrieved from http://www.smartpls.com

Rockart, J. F. (1982). Current uses of the critical success factors process. In Proceedings of the Fourteenth Annual Conference of the Society for Information Management, Chicago, IL.

Schade, J., Schlag, B., et al. (2000). Acceptability of urban transport pricing. Finland: Valtion Taloudellinen Tutkimuskeskus Helsinki.

Schlag, B., \& Schade, J. (2000). Public acceptability of traffic demand management in Europe. Traffic Engineering+ Control, 41(8), 314-18.

Seelhofer, D., \& Graf, C. O. (2018). National project management maturity: A conceptual framework. Central European Business Review, 7(2), 1. doi:https://doi.org/10.18267/j.cebr.196

Selmoune, A., Cheng, Q., Wang, L., \& Liu, Z. (2020). Influencing factors in congestion pricing acceptability: A literature review. Journal of Advanced Transportation, (Just Accepted). doi:https://doi.org/10.1155/2020/ 4242964

Shaikh, Z. A., Wagan, A. A., Laghari, A. A., Ali, K., Memon, M. A., \& Sathio, A. A. (2019). The role of software configuration management and capability maturity model in system quality. International Journal of Computer Science and Network Security, 19(11), 114-119. 
Spruit, M., \& Pietzka, K. (2015). Md3m: The master data management maturity model. Computers in Human Behavior, 51, 1068-1076. doi:https://doi.org/10.1016/j.chb.2014.09.030

Stone, M. (1974). Cross-validation and multinomial prediction. Biometrika, 61(3), 509-515. doi:https://doi.org/ 10.1093/biomet/61.3.509

Taiwo, A. A., \& Downe, A. G. (2013). The theory of User Acceptance and Use of Technology (UTAUT): A meta-analytic review of empirical findings. Journal of Theoretical \& Applied Information Technology, 49(1), 48-58.

Takim, R., Abdul-Rahman, R., Ismail, K., \& Egbu, C. (2008). The acceptability of Private Finance Initiative (PFI) scheme in Malaysia. Asian Social Science, 4(12), 71-82. doi:https://doi.org/10.5539/ass.v4n12p71

Tang, L., \& Shen, Q. (2013). Factors affecting effectiveness and efficiency of analyzing stakeholders' needs at the briefing stage of public private partnership projects. International Journal of Project Management, 31(4), 513-521. doi:https://doi.org/10.1016/j.ijproman.2012.10.010

The Open Group. (2017). Open Information Security Management Maturity Model (O-ISM3). Retrieved from https://www.ism3.com/

Thornhill, A., Saunders, M., \& Lewis, P. (2009). Research methods for business students. Essex: Pearson Education Ltd.

Watts, S. (2018). CMMI: An introduction to capability maturity model integration - BMC blogs. Retrieved from https://bit.ly/2ZVJvuz

Weaver, P. (2007). The origins of modern project management. In Fourth Annual PMI College of Scheduling Conference, Vancouver, Canada.

Wijethilake, C., \& Lama, T. (2019). Sustainability core values and sustainability risk management: Moderating effects of top management commitment and stakeholder pressure. Business Strategy and the Environment, 28(1), 143-154. doi:https://doi.org/10.1002/bse.2245

Wong, K. K. K. (2013). Partial Least Squares Structural Equation Modeling (PLS-SEM) techniques using SmartPLS. Marketing Bulletin, 24(1), 1-32.

Yalegama, S., Chileshe, N., \& Ma, T. (2016). Critical success factors for community-driven development projects: A Sri Lankan community perspective. International Journal of Project Management, 34(4), 643-659. doi:https:// doi.org/10.1016/j.ijproman.2016.02.006

Yang, J. (2010). A framework for stakeholder management in construction projects (Doctoral dissertation). The Hong Kong Polytechnic University, Hong Kong.

Young, R., \& Jordan, E. (2008). Top management support: Mantra or necessity? International Journal of Project Management, 26(7), 713-725. doi:https://doi.org/10.1016/j.ijproman.2008.06.001

Young, R., \& Poon, S. (2013). Top management support-almost always necessary and sometimes sufficient for success: Findings from a fuzzy set analysis. International Journal of Project Management, 31(7), 943-957. doi:https://doi.org/10.1016/j.ijproman.2012.11.013 